\title{
HEAT TRANSFER ENHANCEMENT AND PRESSURE DROP OF GROOVED ANNULUS OF DOUBLE PIPE HEAT EXCHANGER
}

\author{
Putu Wijaya Sunu*, I Made Rasta
}

\author{
Mechanical Engineering Department, Bali State Polytechnic, Bali, Indonesia \\ * corresponding author: wijayasunu@pnb.ac.id
}

\begin{abstract}
This investigation was performed to experimentally investigate the enhancement of heat transfer and the friction of an annulus in a double pipe heat exchanger system with rectangular grooves in the turbulent flow regime. The shell is made of acrylic and its diameter is $28 \mathrm{~mm}$. The tube is made of aluminium and its diameter is $20 \mathrm{~mm}$. Grooves were incised in the annulus room with a circumferential pattern, with a groove space of $2 \mathrm{~mm}$, a distance between the grooves of $8 \mathrm{~mm}$ and a groove height of $0.3 \mathrm{~mm}$. The experiments consist of temperature and pressure measurement and a flow visualization. Throughout the investigation, the cold fluid flowed in the annulus room. The Reynold number of cold fluid varied from about 31981 to 43601 in a counter flow condition. The volume flow rate of hot fluid remains constant with Reynold number about 30904. Result showed the effect of grooves, which are applied in the annulus room. The grooves induce the pressure drop, the pressure drop in the grooved annulus was greater by about $15.88 \%$ to $16.72 \%$ than the one in the smooth annulus. The total heat transfer enhancement is of 1.09-1.11. Moreover, the use of grooves in the annulus of the heat exchanger not only increase the heat transfer process, but also increase the pressure drop, which is related to the friction factor.
\end{abstract}

KEYWORDS: heat transfer; friction factor; circumferential rectangular grooves; annulus.

\section{INTRODUCTION}

Heat exchanger is the most important device for handling the thermal energy in many industrial applications, such as power plants, waste heat recovery, chemical, automotive, food handling, refrigeration and air conditioning and many other application. The important parameters of a heat exchanger are temperature of fluid at the inlet and outlet, flowrate of each fluid and the pressure drop [1. More reasons to consider the application of a heat exchanger are simplicity and easy maintenance. The double pipe heat exchanger is the best candidate for these. To improve the thermal performance of a heat exchanger, many techniques have been developed. One of the surface modifications for an increase of the heat transfer in the turbulence flow are grooves. Groove, as a passive technique, was developed for these applications, because it does not require additional energy, needs no auxiliary power, is quite simple and reduces the weight the of heat exchanger. Therefore, it is widely used in modern heat exchangers and other cooling equipment [2].

The grooves increase the surface area with a little change in diameter and potentially improves not only heat transfer, but also pressure drop. Many investigations have been done to improve the flow characteristics and friction around grooves [2 2]. In past years, most researches focused on rectangular grooves [10 16]. Also studies on various shapes of grooves has been done to improve the flow and flow structure details [17-20].

Over the years, many researches on the fluid flow through the grooves and corrugated tubes and their influence on the heat transfer characteristics have been carried out 21 28]. Although many researches have focused on the groove's shape and the flow structure correlated to a heat transfer enhancement on various applications, few have been done on the annulus of the heat exchanger. Thus, this study fills an important gap in the literature by demonstrating and describing the feasibility of these surface techniques for an annulus application. The specific objective and the scope of this presented work is to evaluate the performance of the heat transfer and to observe the flow phenomenon and friction through the grooved annulus in a double pipe heat exchanger.

\section{EXPERIMENTAL APPARATUS AND METHOD}

The sketch of the experiment apparatus for this investigation is shown in Figure 1. The experiment apparatus was designed to determine the pressure drop, heat transfer and flow visualization. This study used a counter flow in flow direction and water as a working fluid. In counter flow heat exchanger, the hot side inlet temperature is in contact with the cold side outlet temperature and vice versa. The experiment installation consisted of two centrifugal pumps that circulates hot and cold water through a pipe system loop. Rotameter was installed for varying the volume flow rate of the hot and cold fluid. A minimum of $11 \mathrm{l} / \mathrm{min}$ was used and it was increased up to $15 \mathrm{l} / \mathrm{min}$. This flowrate correlated to the Reynolds number $R e$ 


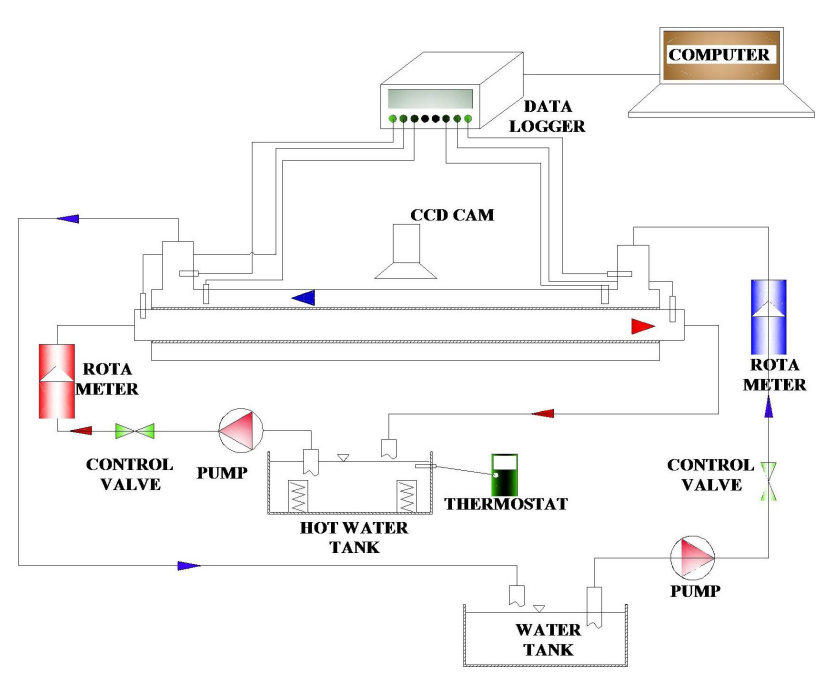

FIGURE 1. The schematic representation of the experiment apparatus set-up.

of the annulus room that was about 31981 and 43610, respectively. Meanwhile, the $R e$ for hot fluid was maintained constant at about 30904. The hot water temperature was $50 \pm 0.50^{\circ} \mathrm{C}$ and the cold water temperature was $30 \pm 0.5^{\circ} \mathrm{C}$.

The heat exchanger test section was a $50 \mathrm{~cm}$ long a tube diameter of $20 \mathrm{~mm}$ and a shell diameter of $28 \mathrm{~mm}$. The tube was made of aluminium and the shell side was made of acrylic tube for easier flow visualization. The annulus room was etched by circumferentialrectangular grooves on outer surface of the tube side. The grooves were formed by a conventional etching technique. K-type thermocouples were used to measure the temperature of the inlet and outlet of the hot and cold fluid in the test section. The signal from thermocouple was then digitalized using a data logger and recorded in a computer memory for $600 \mathrm{~s}$. Pressure transducers MPX $5050 \mathrm{D}$ were used in the pressure measurement, which took place at the upstream and downstream of the annulus section with the sampling frequency of $10 \mathrm{~Hz}$. Dyes were used as the media for visualization and recorded with a high speed camera at $240 \mathrm{fps}$.

\subsection{DATA PROCESSING}

The aim of this current investigation is to determine the heat transfer characteristics and friction in a grooved annulus of a double pipe heat exchanger. The parameters of interest are the Reynolds number $R e$, friction factor $f$, heat transfer $Q$, NTU and effectiveness $\varepsilon$.

The Reynolds number is given by

$$
R e=\frac{u D_{\mathrm{h}}}{v} .
$$

The Hydraulic diameter of annulus is calculated from

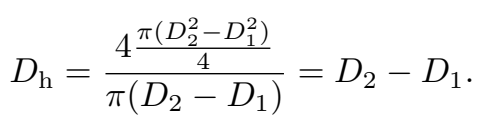
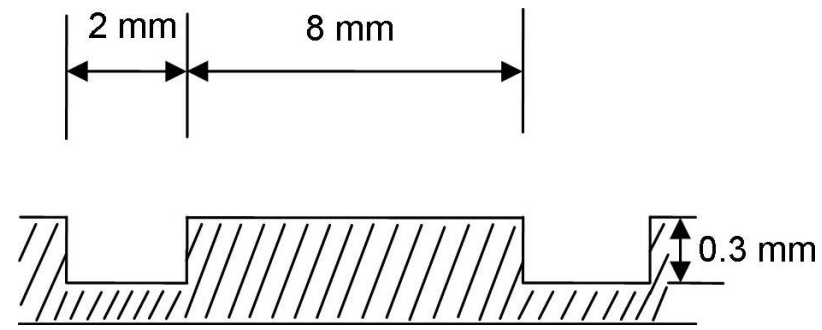

FiguRE 2. Schematic of groove.

The friction factor $f$ calculated from pressure drop as

$$
f=\frac{2 \Delta P}{\frac{l}{D_{\mathrm{h}}} \rho u^{2}} .
$$

The heat transfer, the heat transfer enhancement and heat capacity ratio defined as

$$
\begin{gathered}
Q=\dot{m} C_{\mathrm{p}} \Delta T, \\
E_{\mathrm{h}}=\frac{Q_{\text {groove }}}{Q_{\mathrm{smooth}}}, \\
c=\frac{C_{\text {min }}}{C_{\max }} .
\end{gathered}
$$

The NTU and effectiveness follow

$$
\begin{gathered}
\mathrm{NTU}=\frac{U A}{C_{\min }} ; \quad U=\frac{\mathrm{NTU} C_{\min }}{A}, \\
\varepsilon=\frac{1-\exp (-\mathrm{NTU}(1-c))}{1-c \exp (-\mathrm{NTU}(1-c))} .
\end{gathered}
$$

\subsection{UNCERTAINITY ANALYSIS}

Experimental uncertainty was determined by the deviation of the parameters, including temperature, pressure, and flow rate. The precision of temperature data acquisitions is $\pm 0.1^{\circ} \mathrm{C}$, the pressure drop was measured by pressure transducers with the accuracy of $\pm 2.5 \%$, the flow rate was measured by a rotameter with a full scale accuracy of $\pm 5 \%$. The uncertainty of experimental results could be expressed as follows [29]:

$$
u_{\mathrm{m}}= \pm\left(\left(\frac{\Delta T}{T}\right)^{2}+\left(\frac{\Delta P}{P}\right)^{2}+\left(\frac{\Delta V}{V}\right)^{2}\right)^{1 / 2}
$$

therefore the experiment uncertainty was about $5 \%$

\section{Results And Discusscion}

Preliminary experiments were done using the smooth annulus of a double pipe heat exchanger to determine the amount of the pressure drop. This data were then used as a comparison to that of the grooved annulus. Figure 3 a shows the overall pressure drop of a double pipe heat exchanger at various values of Reynolds Number. From Figure 3a, it can be seen that the application of grooves on the annulus room of a double pipe heat exchanger leads to a substantial increase of pressure drop, about $15.82 \%$ to $16.72 \%$ compared to that of the smooth annulus. The grooves provided the enhancing turbulence by increasing the recirculation 

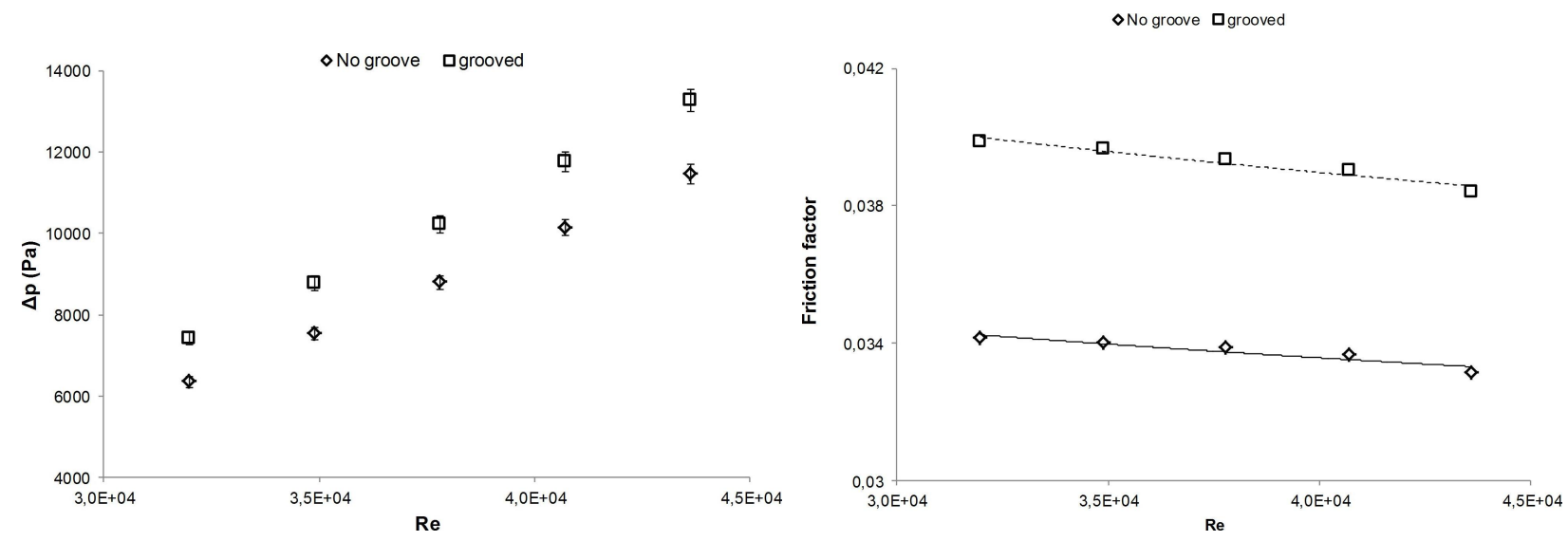

FiguRE 3. Pressure drop and friction factor of double pipe heat exchanger: (a) Overall pressure drop; (b) Friction factor.

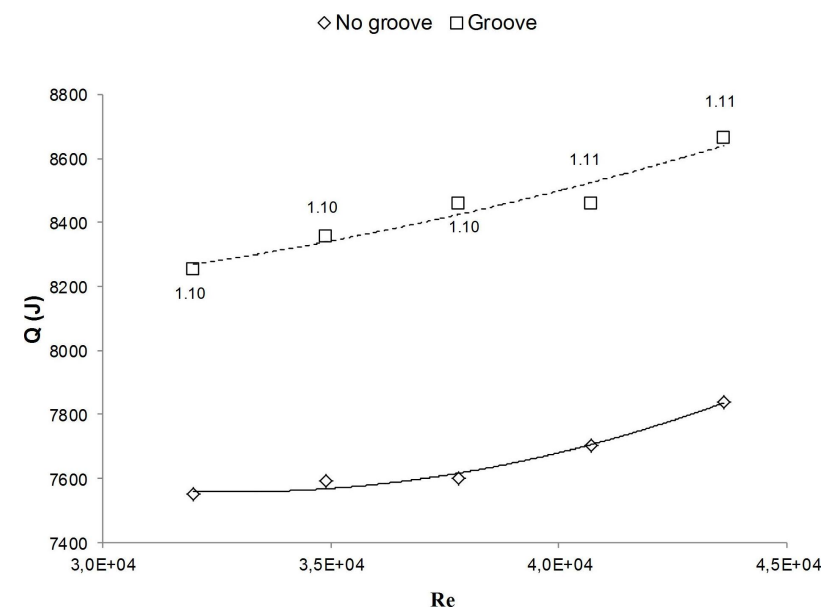

Figure 4. The variation of heat transfer with Reynold number.

region near the pipe wall. This phenomenon tends to increase the shear stress and the pressure drop. Figure 3 a indicates linear pressure drop for increased Re of the annulus. The influence of using circumferentialrectangular grooves towards friction of the annulus is displayed in Figure $3 \mathrm{p}$. In the Figure 3p, it can be seen that the application of grooved annulus tends to increase the friction factor when compared to the one of the smooth annulus. The friction factor decreases with the increasing Re. The friction loss is mainly caused by the increased surface area, higher recirculation intensity and stronger vortex flow around the groove (Figure 7).

Figure 4 shows the total heat transfer by the heat exchanger for a period of time. It was found out that the heat transfer increased with the increase of the Reynolds number and the grooved annulus gave higher total heat transfer than the smooth annulus. From this figure, the heat transfer enhancements were calculated using (5). The highest enhancement at the highest $R e$ was observed at 1.11. The swirl flow on the fluid near the pipe wall generated by the groove was responsible for thinning the thermal boundary

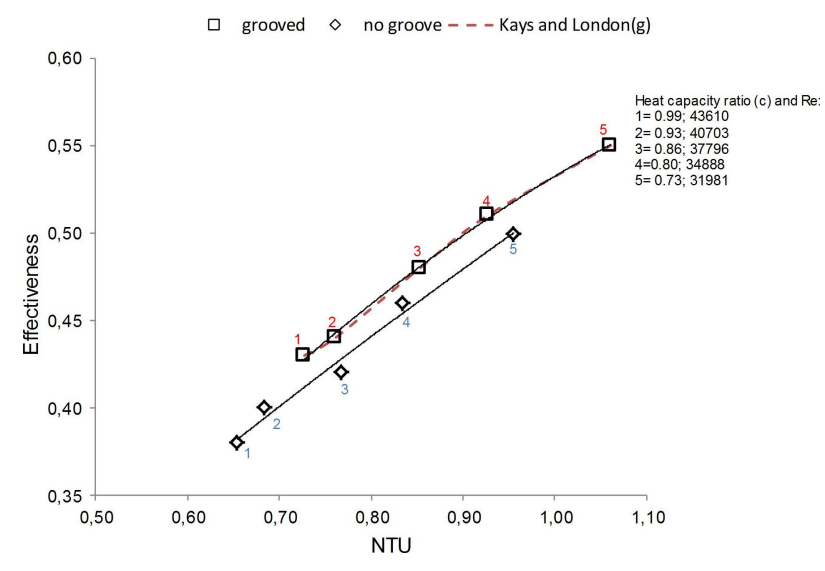

FIgURE 5. Effectiveness and NTU relationship.

layer and made the heat transfer higher through the fluid.

The effectiveness and the NTU relationship of the investigation were presented in Figure 5. Numbers 1 to 5 represent the heat capacity ratio $c$ of this experiment at specific Reynolds number Re. The NTU and effectiveness $\varepsilon$ of the grooved annulus were compared to that of the smooth annulus. It was found out that the heat capacity ratio influenced the NTU and effectiveness. Figure 5 shows that the increased heat capacity ratio caused a decrease in the NTU and effectiveness. At the same heat capacity ratio, the effectiveness and the NTU of the grooved annulus were higher than those of the smooth annulus. The increase of effectiveness is indicated by the increased rate of the actual heat transfer. While the increase of the NTU indicates an increase of the overall heat transfer coefficient and surface area $U A$ value. The grooves lead to an increase of turbulence, therefore, the fluid interaction and momentum also increase. The effectiveness and the NTU of the grooved annulus were close to the results from [30].

To give more detailed information about the heat transfer phenomenon in the grooved annulus, a visualization technique was developed. The flow structures over annulus were visualized using a dye technique to 

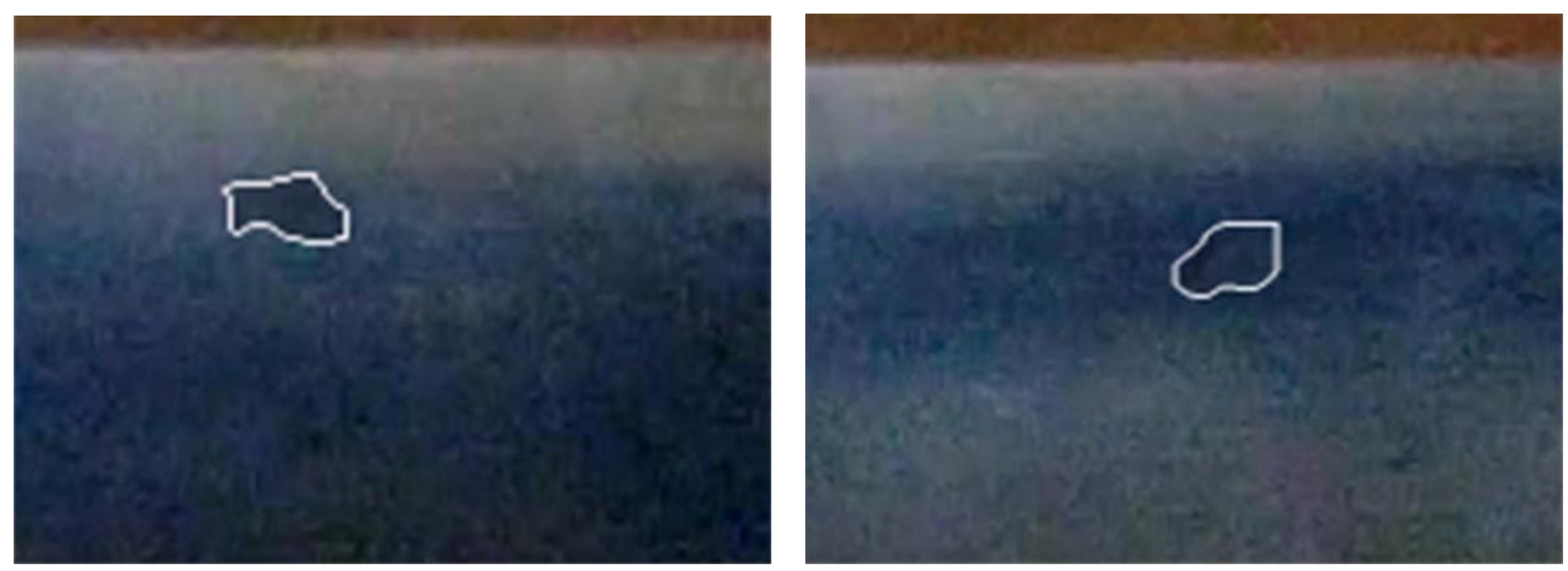

FigURE 6. Visualisation of the flow in the smooth double pipe heat exchanger at $240 \mathrm{fps}$ : (a) initial condition; (b) condition after $0.004 \mathrm{~s}$.
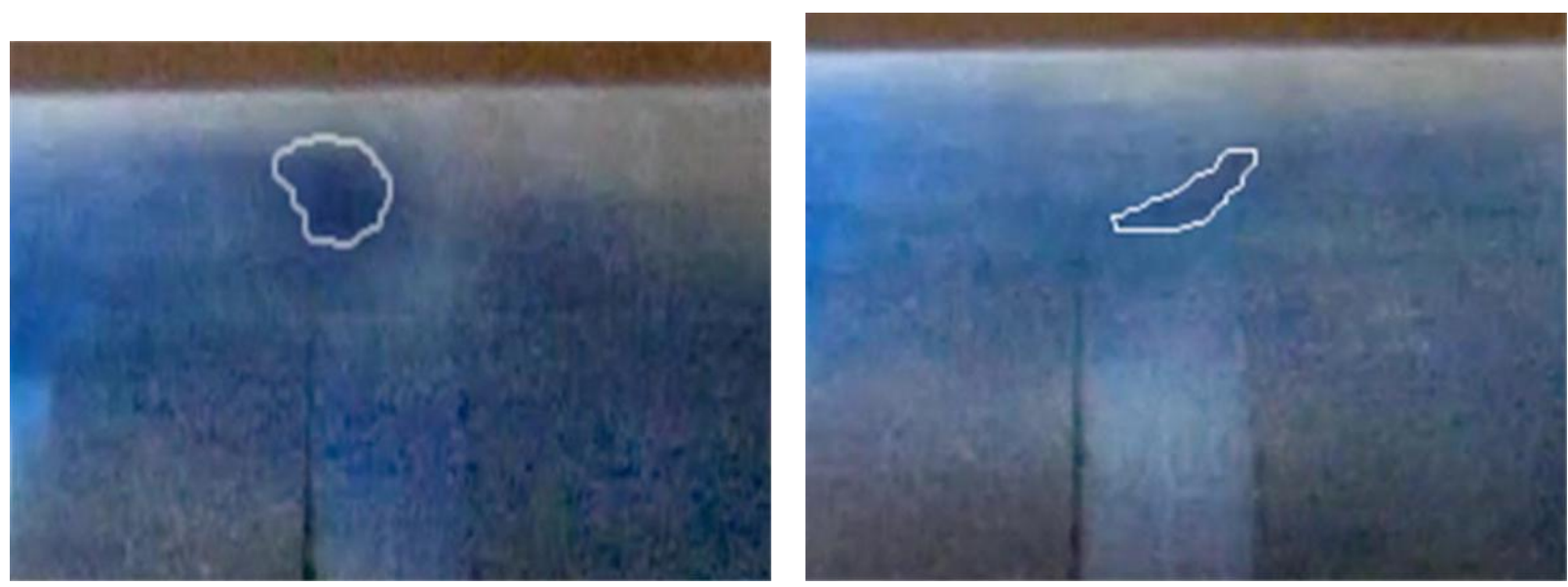

Figure 7. Visualisation of the flow in the grooved double pipe heat exchanger at $240 \mathrm{fps}$. (a) initial condition; (b) condition after $0.004 \mathrm{~s}$.

give more understanding about what happens inside the groove valley. The images were transferred to a computer for image processing and analysis as shown in Figures 6 and 7. The small round shape is the fluid lump considered to be the vortex near the groove.

The change of the vortex dimensions indicates a change of the velocity gradient inside it. After $0.004 \mathrm{~s}$, in the smooth annulus of the double pipe heat exchanger (Figure 6), there can be clearly seen that there is a small change of the vortex dimensions. This phenomenon indicates a small gradient of the fluid velocity in the annulus space.

However, in the case of the grooved annulus of a double pipe heat exchanger, the vortex dimensions became smaller and the vortices tend to fall into the groove valley. The vortices crept inside the valley and increased the velocity gradient and shear stress. The presence of a velocity gradient was proved by the value of pressure drop (Figure 3a). It is well known that the pressure drop is proportional to the square of the velocity. This phenomenon increases the turbulence intensity, recirculation and fluid momentum. This process will lacerate the thermal boundary layer so that the obstacles of the heat transfer will be smaller.
This phenomenon is increasing the heat transfer rate of the grooved double pipe heat exchanger.

\section{Conclusions}

An experimental investigation was carried out for a heat transfer enhancement, the NTU, effectiveness $\varepsilon$, pressure drop and flow visualization of a grooved annulus of a double pipe heat exchanger. The main scope of this study was to compare a grooved double pipe heat exchanger with a smooth double pipe heat exchanger. Moreover, new and simple flow visualizations were developed. The result can be summarized as follows:

(1.) The heat transfer increased with the increase of the $R e$. For the grooved double pipe heat exchanger, the heat transfer enhancement was about 1.09-1.11 and the pressure drop increased by about 15.82 $16.72 \%$.

(2.) The effectiveness increased with the decrease of the heat capacity ratio and increased the NTU value.

(3.) Grooves influence the flow structure in the annulus of a double pipe heat exchanger. 


\section{LIST OF SYMBOLS}

$u$ fluid velocity $\left[\mathrm{m} / \mathrm{s}^{2}\right]$

$A$ surface area $\left[\mathrm{m}^{2}\right]$

$v$ kinematic viscosity $\left[\mathrm{m}^{2} / \mathrm{s}\right]$

$l$ pipe long $[\mathrm{m}]$

$\dot{m}$ mass flowrate $[\mathrm{kg} / \mathrm{s}]$

$\rho$ fluid density $\left[\mathrm{kg} / \mathrm{m}^{3}\right]$

$D_{\mathrm{h}}$ hydrolic diameter [m]

$D_{1} \quad$ outer diameter of tube side [m]

$D_{2}$ inner diameter of shell side [m]

$\Delta P$ pressure drop $[\mathrm{Pa}]$

$\Delta T$ temperature difference of hot/cold fluid in time period $\left[{ }^{\circ} \mathrm{Cs}\right]$

$Q$ heat transfer $[\mathrm{J}]$

$C_{\mathrm{p}}$ specific heat $\left[\mathrm{J} / \mathrm{kg}^{\circ} \mathrm{C}\right]$

$E_{\mathrm{h}}$ heat transfer enhancement

$\varepsilon \quad$ effectiveness

$U$ overall heat transfer coefficient $\left[\mathrm{W} / \mathrm{m}^{2}{ }^{\circ} \mathrm{C}\right]$

$C_{\text {min }}$ the smallest heat capacity rate $\left[\mathrm{W} /{ }^{\circ} \mathrm{C}\right]$

$C_{\max }$ the highest heat capacity rate $\left[\mathrm{W} /{ }^{\circ} \mathrm{C}\right]$

$c$ heat capacity ratio

NTU number of transfer unit

\section{REFERENCES}

[1] Jan Opatril, Jan Havlik, Ondrej Batros, Tomas Dlouhy. An experimental assessment of the plate heat exchanger characteristics by wilson plot method. Acta Polytechnica 56(5), 2016, 367-372.

[2] Sunu P.W., ING Wardana, A.A.Sonief, Nurkholis Hamidi. The effect of wall groove numbers on pressure drop in pipe flows. Int. J. Fluid Mech. Resch., 42(2), $2015,119-130$.

[3] Hongwei, M.A., Qiao TIAN, and Hui WU. Experimental study of turbulent boundary layers on groove/smooth flat surfaces. J. of Thermal Science 14(3), 2005, 93-97.

[4] Litvinenko, Y.A., Chernoray, V.G., Kozlov, V.V., Loefdahl, L., Grek, G.R. and Chun, H.H. The influence of riblets on the development of a structure and its transformation into a turbulent spot. Doklady Physics 51(3), 2006, 144-147.

[5] Sunu P.W. The characteristics of increased pressure drop in pipes with grooves. Adv. Studies Theor. Phys., Vol. 9, 2015, no. 2, 57-61.

[6] Sunu P.W., ING Wardana, A.A.Sonief, Nurkholis Hamidi. Flow behavior and friction factor in internally grooved pipe wall. Adv. Studies Theor. Phys., Vol. 8, 2014 , no. $14,643-647$.

[7] Sunu P.W., ING Wardana, A.A.Sonief, Nurkholis Hamidi. Optimal grooves number for reducing pressure drop. Contemporary Engineering Sciences, Vol. 9, 2016, no. $22,1067-1074$

[8] Ding G., Haitao Hu, Huang X., Bin Deng, Yifeng Gao. Experimental investigation and correlation of two-phase frictional pressure drop of R410A-oil mixture flow boiling in a $5 \mathrm{~mm}$ microfin tube. International Journal of Refrigeration 32, 2009, 150-161.
[9] Frohnapfel, B., Lammers, P., Jovanović, J. The Role Of Turbulent Dissipation For Flow Control Of Near-Wall Turbulence. New Res. In Num. and Exp. Fluid Mech. VI, NNFM 96, 2007, 268-275.

[10] S. Lorenz, D. Mukomilow, W. Leiner. Distribution of the heat transfer coefficient in a channel with periodic transverse grooves. Exp. Therm. Fluid Sci. 11, 1995, 234-242.

[11] T. Adachi and H. Uehara. Correlation between heat transfer and pressure drop in channels with periodically grooved parts. Int. J. Heat Mass Transfer 44, 2001, $4333-4343$.

[12] S. Eiamsa-ard and P. Promvonge. Numerical study on heat transfer of turbulent channel flow over periodic grooves. Int. Commun. Heat Mass Transfer 35, 2008, 844-852.

[13] S. Eiamsa-ard and P. Promvonge. Thermal characteristics of turbulent rib-grooved channel flows. Int. Commun. Heat Mass Transfer 36, 2009, 705-711.

[14] T. Adachi, Y. Tashiro, H. Arima, Y. Ikegami. Pressure drop characteristics of flow in a symmetric channel with periodically expanded grooves. Chem. Eng. Sci. 64, 2009, 593-597.

[15] M. Jain, A. Rao, K. Nandakumar. Numerical study on shape optimization of groove micromixers. Microfluid Nanofluid 15, 2013, 689-699.

[16] C. Wang, Z.L. Liu, G.M. Zhang, M. Zhang. Experimental investigations of flat plate heat pipes with interlaced narrow grooves or channels as capillary structure. Exp. Therm. Fluid Sci. 48, 2013, 222-229.

[17] Sutardi and C.Y. Ching. Effect of Transverse Square Groove on a Turbulent Boundary Layer. Experimental Thermal and Fluid Science, 20, 1999, 1-10.

[18] Lee, S.J. and Y.G. Jang. Control Of Flow Around A Naca 0012 Airfoil With A Micro-Riblet Film. Journal of Fluid and Structure, 20, 2005, 659-672.

[19] Shan Huang. VIV Suppression Of A Two Degree Of Freedom Circular Cylinder And Drag Reduction Of A Fix Circular Cylinder By The Use Of Helical Grooves. Journal of Fluids and Structures, 27, 2011, 1124-1133.

[20] Lee, S.J. and S.H. Lee. Flow Field Analysis Of A Turbulent Boundary Layer Over A Riblet Surface. Experiments in Fluids, 30, 2001, 153-166.

[21] Sunu P.W., Anakottapary D.S., Santika W.G. Temperature approach optimization in the double pipe heat exchanger with groove. Matec web of conference 58, 04006, 2016. DOI:10.1051/matecconf/20165804006

[22] Aroonrat, K., Jumpholkul, C., Leelaprachakul, R., Dalkilic, A.S., Mahian, O., Wongwises, S. Heat transfer and single-phase flow in internally grooved tube. International Communication in Heat and Mass Transfer 42, 2013, 62-68.

[23] Katoh, K., K.S. Choi, T. Azuma. Heat-transfer Enhancement and Pressure Loss by Surface Roughness in Turbulent Channel Flows. International Journal of Heat and Mass Transfer, 43, 2000, 4009-4017.

[24] Jian Liu, Gongnan Xie, Terrence W. Simon. Turbulent flow and heat transfer enhancement in rectangular channels with novel cylindrical grooves. International Journal of Heat and Mass Transfer 81, 2015, 563-577. 
[25] K. Bilen, M.Cetin, H.Gul, T. Balta. The investigation of groove geometry effect on heat transfer for internally grooved tubes. Appl.Therm.Eng. 29, 2009, 753-761.

[26] R.Kamali, A.Binesh. The importance of rib shape effects on the local heat transfer and flow friction characteristics of square ducts with ribbed internal surfaces. Int. Commun. Heat Mass Transf. 35, 2008, 1032-1040.

[27] Ali Najah Al-Shamani, K.Sopian, H.A. Mohammed, Sohif Mat, Mohd Hafidz Ruslan, Azher M. Abed.

Enhancement heat transfer characteristics in the channel with trapezoidal rib-groove using nanofluids. Case Studies in Thermal Engineering, 5, 2015, 48-58.
[28] Hamed Sadighi Dizaji, Samad Jafarmadar, Farokh Mobadersani. Experimental studies on heat transfer and pressure drop characteristics for new arrangements of corrugated tubes in a double pipe heat exchanger. International Journal of Thermal Sciences, 96, 2015, 211-220.

[29] Moffat, R. J. Describing the uncertainties in experimental results. Experimental Thermal and Fluid Science, 1, 1988, 3-17.

[30] Kays W.M and London A.L. Compact Heat Exchanger. 3rd ed. New York: McGraw-Hill, 1984. 